\title{
David Oliver: Rehabilitation is part of medicine
}

\author{
David Oliver consultant in geriatrics and acute general medicine, Berkshire
}

I spoke recently at a conference on how future hospital models must adapt to older people's needs. Conversation afterwards turned to doctors' careers and what might make acute and general internal medicine more appealing. Someone pulled out the chestnut (one sadly familiar to geriatricians) that "doctors don't go into medicine to do social work."

I have problems with this viewpoint.

Let me translate "social work" here: it means multidisciplinary rehabilitation and discharge planning for people with frailty, complex comorbidity, disability, or dementia.

Firstly, such patients are the biggest users of acute services. Patients over 65 account for around two thirds of acute hospital admissions and over 80s for a quarter of bed days. ${ }^{1}$ One in four acute beds is occupied by someone with dementia. ${ }^{2}$ Multiple comorbidity is the norm in over 60 s attending the emergency department, ${ }^{3}$ and frailty is highly predictive of hospital admission. ${ }^{4}$ Looking after these patients is now everyone's business. ${ }^{15}$

In any aspect of adult hospital medicine, you will encounter (generally older) patients with complex biopsychosocial problems. If we are serious about patient centred care, we can't marginalise them.

Secondly, a patient who could walk last week but is now falling or immobile, or who was lucid but is now delirious, who had intact bones but has now broken one, has a diagnosable and modifiable medical problem. The notion that he or she is a "social" admission ${ }^{6}$ ignores the medical skill and knowledge needed to help patients regain former levels of independence and return home (or vice versa). Comprehensive geriatric assessment is such a multidisciplinary biopsychosocial approach. Meta-analysis of 22 trials shows that doing this well has long term benefits for inpatients' survival and independence for months after they leave hospital.

Thirdly, most older patients admitted acutely to hospital have some functional impairment already, ${ }^{89}$ but most also lose some ability in common activities such as standing, walking, or dressing while on the wards, ${ }^{9}{ }^{10}$ and they go home short of baseline even if the acute problem has stabilised. ${ }^{11}$ So most need, and benefit from, a skilled multidisciplinary approach involving allied health professionals. Many need referral to ongoing health and care services to continue their recovery outside hospital. That's the way of modern healthcare.

So, next time I discuss future hospital models I'll wonder out loud whether medical training will ensure that all doctors have rudimentary knowledge about helping older people back onto their feet, an understanding of community services, and full commitment to rehabilitation rather than assuming it's someone else's job.

We mustn't socialise problems that medical skills can help tackle. A patient with a fall, a fracture, or loss of mobility needs more than just a social approach.

Competing interests: I have read and understood the BMJ policy on declaration of interests and have no relevant interests to declare. Provenance and peer review: Commissioned; not externally peer reviewed.

NHS Benchmarking Network. Raising standards through sharing excellence. Apr 2015. www.nhsbenchmarking.nhs.uk/CubeCore/.uploads/NHSBNOPReport2014Circ.pdf.

Alzheimer's Society. Counting the cost: caring for people with dementia on hospital wards. 2009. www.alzheimers.org.uk/site/scripts/download info.php?filelD $=787$.

3 Blunt I, Health Foundation, Nuffield Trust; QualityWatch. Focus on: A\&E attendances. 2014. www.nuffieldtrust.org.uk/sites/files/nuffield/publication/140724_focus_on_ae_ attendances.pdf.

4 Young J. Changing care systems for people with frailty. 2 Dec 2015. www. healthcareconferencesuk.co.uk/news/changing-care-systems-for-people-with-frailty.

5 Royal College of Physicians. Hospitals on the edge? The time for action. 10 Sep 2015. www.rcplondon.ac.uk/guidelines-policy/hospitals-edge-time-action.

6 Oliver D. "Acopia" and "social admission" are not diagnoses: why older people deserve better. J R Soc Med 2008;101:168-74.

7 Ellis G, Whitehead MA, Robinson D, O'Neill D, Langhorne P. Comprehensive geriatric assessment for older adults admitted to hospital: meta-analysis of randomised controlled trials. BMJ 2011;343:d6553.

8 Hubbard RE, O'Mahony MS, Cross E, et al. The ageing of the population: implications for multidisciplinary care in hospital. Age Ageing 2004;5:479-82.

9 Mudge AM, Kasper K, Clair A, et al. Recurrent readmissions in medical patients: a prospective study. J Hosp Med 2011;6:61-7.

10 Covinsky KE, Palmer RM, Fortinsky RH, et al. Loss of independence in activities of daily living in older adults hospitalized with medical illnesses: increased vulnerability with age. Am Geriatr Soc 2003:51:451-8.

11 NHS Benchmarking Network. National audit of intermediate care: summary report. 2014 www.nhsbenchmarking.nhs.uk/CubeCore/.uploads/NAIC/NAICSummaryReport2014.pdf. 